\title{
The Role of Personality Traits, Attachment Style, and Satisfaction With Relationships in the Subjective Well-Being of Americans, Portuguese, and Mozambicans
}

\author{
Iolanda Costa Galinha', Shigehiro Oishi ${ }^{2}$, Cícero Pereira ${ }^{3}$, \\ Derrick Wirtz ${ }^{4}$, and Francisco Esteves ${ }^{5}$
}

\begin{abstract}
Personality traits, attachment security, and satisfaction with relationships are each important predictors of subjective well-being (SWB). However, no studies have included these predictors together to analyze the unique contribution of each to SWB. Furthermore, most studies are empirically based in Western/industrialized societies, and few studies include African countries. This article addresses the unique contribution of extroversion, neuroticism, attachment security, and satisfaction with relationships to SWB across three samples of 1,574 university students: 497 from North Carolina (United States of America), 544 from Maputo (Mozambique), and 533 from Lisbon (Portugal). Structural equation modeling analysis showed that in the American sample, emotional stability was a more important predictor of global SWB than satisfaction with relationships. In the Mozambican sample, satisfaction with relationships was far more important as a predictor of SWB than emotional stability. In the Portuguese sample, emotional stability and satisfaction with relationships were equally important predictors of SWB. The main difference between the three samples was the contribution of satisfaction with relationships to SWB. Similarities between the three samples include the low or nonsignificant contributions of extroversion and attachment to SWB, above and beyond the contribution of satisfaction with relationships and neuroticism, suggesting they may be sharing variance in the prediction of SWB.
\end{abstract}

\section{Keywords}

personality, attachment, satisfaction with relationships, subjective well-being, cross-cultural

\footnotetext{
'Autónoma University of Lisbon, Lisbon, Portugal

${ }^{2}$ University of Virginia, Charlottesville, Virginia, USA

${ }^{3}$ Institute of Social Science, University of Lisbon, Lisbon, Portugal

${ }^{4}$ East Carolina University, Greenville, North Carolina, USA

${ }^{5}$ University of Lisbon, Lisbon, Portugal

Corresponding Author:

Iolanda Costa Galinha, Autónoma University of Lisbon, Rua Cruz Sta Apolonia, 64, 3 dto, Lisbon, II00-188,

Portugal.

Email: iolandag@yahoo.com
} 
There is a large body of evidence that personality traits, attachment security, and satisfaction with relationships are each important predictors of subjective well-being (SWB; Diener \& Ryan, 2009; Diener, Suh, Lucas, \& Smith, 1999). However, to our knowledge, there have been no studies that included personality traits, attachment, and satisfaction with relationships together to analyze the unique contributions of each variable to SWB. Furthermore, most studies and theories in psychology are developed and empirically based in Western/industrialized societies, assuming that psychological processes are universal (Henrich, Heine, \& Norenzayan, 2010). Moreover, despite much cross-cultural research in the area of SWB (see Diener, Oishi, \& Lucas, 2003, for a review), few studies have included samples from nonindustrialized cultures, particularly Middle Eastern and African countries. The present study addresses both of these limitations of past research by using structural equation modeling (SEM) to examine (a) the unique contribution of Big Five personality traits, attachment, and relationship satisfaction to SWB and (b) whether the role of personality traits, attachment style, and relationship satisfaction in SWB varies across three nations: the United States, Portugal, and Mozambique. A third goal is to explore mediation of the effects of these variables on SWB. Specifically, we cross-culturally examine (c) attachment style and satisfaction with relationships as mediators of the effect between personality and SWB and attachment style as a mediator of the effect between personality and satisfaction with relationships.

\section{The Predictors of Subjective Well-Being}

SWB is a broad construct that includes satisfaction with life as a whole and with various life domains, the frequent experience of positive affect and the relatively infrequent experience of negative affect (Diener \& Ryan, 2009; see Arthaud-Day, Rode, Mooney, \& Near, 2005; Galinha $\&$ Ribeiro, 2008, for empirical support). In the following section, we provide a brief overview of the three predictors of SWB examined in the present study: personality, attachment, and satisfaction with relationships.

Personality and SWB. Personality can be defined as consisting of individual trait characteristics that are mainly determined by innate disposition (Costa \& McCrae, 2000) but also shaped by environmental experiences (Sanson, Hamphil, \& Smart, 2002). According to the Five Factor model (Digman, 1990), personality can be comprehensively described along the five broad dimensions of neuroticism, extroversion, openness to experience, agreeableness, and conscientiousness. Among these five traits, extroversion and neuroticism are the most consistently and strongly related to SWB through their associations with positive affect and negative affect, respectively (Diener \& Biswas-Diener, 2008; Lucas, 2008). Personality has also been associated with the quality of, and satisfaction with, romantic relationships (Karney \& Bradbury, 1995; Kwan, Bond, \& Singelis, 1997). Specifically, extroversion has been positively-and neuroticism negatively—related to romantic relationship quality (White, Hendrick, \& Hendrick, 2004).

Attachment and SWB. Attachment style is a relatively stable characteristic related to expectations about significant relationships with others. It is considered to be a joint product of early experiences in attachment relationships and current cognitive and social contexts (Mikulincer \& Shaver, 2007). The contribution of genes, however, is not excluded from the process (Crawford et al., 2007). According to Mikulincer and Shaver (2007), attachment style develops as a result of the individual's experiences with attachment figures and is based upon an appraisal of the figure's availability and responsiveness, producing an adaptive regulation of one's emotions in response. Repeated experiences with caregivers are responsible for a sense of attachment security or insecurity and will constitute schematic mental representations of these experiences. These schematic mental representations will constitute working models of action that are relatively stable, although they are open to change. Attachment insecurity is characterized by hyperactivation (anxiety) or 
deactivation (avoidant) as an emotion regulatory response. Secure attachment is characterized by positive expectations about the availability and effectiveness of social support and the willingness to ask others for help when needed.

Empirical studies have found results consistent with attachment theory. Secure attachment is associated with positive emotions during social interaction (Pietromonaco \& Barrett, 1997), as well as greater happiness, lower negative affect, and fewer psychiatric symptoms (see Mikulincer $\&$ Shaver, 2007, for a review). Attachment insecurities - anxiety, avoidance, or both — are associated with heightened distress and diminished well-being (e.g., Birnbaum, Orr, Mikulincer, \& Florian, 1997) and negatively associated with global happiness (Tomlinson, Carmichael, Reis, \& Aron, 2010). When alone, insecure people are more likely to feel lonely, irritable, and anxious (Torquati \& Raffaelli, 2004). Anxious attachment may contribute to the development of maladaptive affect regulation strategies that, in turn, may contribute to negative mood and interpersonal problems (Diamond, Hicks, \& Otter-Henderson, 2008), to the report of relatively low levels of romantic relationship satisfaction (Mikulincer \& Shaver, 2005), and to lower positive emotions (Tidwell, Reis, \& Shaver, 1996). For avoidance deactivating strategies, results are more complex. Several studies yielded no associations with self-report measures of SWB and global distress but with a pattern of heightened reports of somatic complaints, substance abuse and conduct disorder, or schizoid and avoidant personality disorders (Mikulincer \& Shaver, 2007).

Satisfaction with relationships and SWB. Social relationships are central to human functioning and constitute an essential factor in promoting the survival of the species. Relationships are deeply connected to mental (Reis, Collins, \& Berscheid, 2000) and physical health (Cohen, 2004). In a literature review, Lyubomirsky, King, and Diener (2005) pointed out that satisfaction with relationships might be the single most robust predictor of SWB in the research literature. People with high positive affect, happiness, and life satisfaction report more friends and people they can trust, greater social support, and higher satisfaction with interpersonal relationships. In another literature review (Diener \& Biswas-Diener, 2008), the quality and quantity of social relationships were found to be highly correlated with SWB. Social interactions are the most enjoyable points in the day (Kahneman \& Krueger, 2006) and act as a buffer to major life stresses (Myers, 1999). Quality contact with friends was a strong predictor of SWB in a meta-analysis of 286 studies; in older adults, a stronger predictor than even contact with family (Pinquart \& Sörensen, 2000). Loneliness, in turn, has been negatively associated with happiness and positively associated with depression (Seligman, 1991).

Within various social relationships, one important predictor of SWB is romantic/marital satisfaction: Happier individuals report more satisfaction and fulfillment with their marriages (Headey, Veenhoven, \& Wearing, 1991; Myers, 1999), and married people are happier and more satisfied with life than singles, widows, and divorcees. Results are consistent in Europe and in the United States (Helliwell, Barrington-Leigh, Harris, \& Huang, 2009) and across different cultures. However, the benefits of marriage compared to cohabitation are higher in collectivistic societies (Diener, Gohm, Suh, \& Oishi, 2000). Being involved in and being satisfied with a romantic relationship are each important correlates of SWB (Crossley \& Langdridge, 2005; Demir, 2008; Dush \& Amato, 2005).

The predictors of SWB referred to above also show some association with each other. Previous research has pointed out the association between Big Five personality traits and attachment styles. For example, Noftle and Shaver (2006) found that secure attachment was positively correlated with extroversion but not correlated with neuroticism, while ambivalent attachment was negatively correlated with both extroversion and neuroticism. Dismissive attachment was negatively correlated with extroversion and, contrary to expectations, inversely correlated with neuroticism. In a study by Bakker, van Oudenhoven, and van der Zee (2004), the Big Five dimensions explained approximately $20 \%$ of the variance in each attachment scale, indicating that although 
there is some degree of overlap, attachment styles were not redundant with personality. These studies indicate the importance of controlling for the shared variance among the key predictors of SWB. In addition, it is plausible that the well-established association between extroversion and SWB could be due to the fact that extroverts are more likely to develop a secure attachment style and maintain satisfying relationships than introverts. In other words, the association between extroversion and SWB could be mediated by attachment style and satisfaction with relationships, a hypothesis examined in the present study.

\section{Cross-Cultural Differences and Similarities}

Although the importance of personality traits, attachment, and satisfaction with relationships to SWB has been repeatedly demonstrated, most studies have been conducted using North American and Western European samples. In addition, the small number of cross-cultural studies on this topic has been almost exclusively focused on East-West differences (e.g., Kang, Shaver, Sue, Min, \& Jing, 2003; Kwan et al., 1997; Uchida, Kitayama, Mesquita, Reyes, \& Morling, 2008; see Diener et al., 2003; Suh \& Oishi, 2004, for a review). A sampling bias of this sort could, in turn, systematically bias scientific knowledge (Henrich et al., 2010; Norenzayan \& Heine, 2005). To address this limitation of previous research on culture and SWB, we collected data in three nations - the United States, Portugal, and Mozambique - that differ in terms of geography, wealth, culture, and language, following Norenzayan and Heine's research strategy of triangulation.

The triangulation strategy consists of comparing three samples from different cultures. The differences and similarities between the three samples in specific dimensions contribute to understanding the impact of each cultural dimension on the analyzed phenomena. Two cultures can be similar in one dimension but different in others. For example, the United States and Portugal share elements of traditional European/Western culture, in contrast to Mozambique. Thus, if Western traditions are at play in determining the predictors of SWB, then Americans and Portuguese should be fairly similar to each other, and different from Mozambicans. On the other hand, if Portuguese culture and language are at play, then Portuguese and Mozambicans should be similar to each other and different from Americans. Mozambique and Portugal shared nearly 500 years of history, between 1505 and 1975, during the colonization period. This common historic background resulted in an acculturation process that is reflected in several aspects of the Mozambican and Portuguese cultures, such as language. Nevertheless, although Portuguese is the official language of Mozambique, the diversity of the Mozambican languages, estimated between 20 and 32, is a reflection of the broad cultural diversity of the Mozambican territory (Mozambican Government Official Site, 2011).

Furthermore, the United States is the wealthiest and most individualistic country, and Mozambique is the least wealthy and individualistic. If wealth and individualism-collectivism are at play, then Americans and Mozambicans should be most different from each other, and Portuguese should be in between. The International Monetary Fund (IMF), in 2010, ranked the Gross Domestic Product(GDP) of the United States as first among 181 countries (US\$16,282,230), followed by Portugal (38th; US\$229,336) and Mozambique (121st; US\$10,212). Similar relative positions can be found in the 2009 World Bank data (IMF, 2011; World Bank, 2011). Hofstede (1980) described individualism as the tendency within a culture to focus on the individual rather than on the group and collectivism as a tendency within a culture toward gregariousness and group orientation. The concept of individualism-collectivism has been challenged by Oyserman, Coon, and Kemmelmeier (2002); however, despite some limitations and inconsistencies between some measures of the concept, individualism-collectivism has been considered a valid construct (Schimmack, Oishi, \& Diener, 2005). Markus and Kitayama (1991) linked the dimension of individualism-collectivism to the concept of self-construal (a) as independent (a view of oneself 
as an autonomous, bounded, utilitarian agent) or (b) as interdependent (flexible and variable, changing between contexts and relationships).

Veenhoven (1999) linked the construct of individualism-collectivism to national wealth and developmental level. Among poor countries, individualism was negatively associated with happiness, whereas among richer countries individualism was positively associated with happiness. One explanation is that collectivism may be highly functional in a context where people need to cooperate and share their lives to survive and grow. In general, modernized Western countries (e.g., the United States and Britain) are considered to be highly individualistic, whereas developing Eastern nations are more collectivist. It is assumed that African cultures are also collectivist (Triandis, 1989); however, assertions of collectivism have not been empirically tested (Eaton \& Louw, 2000). Portugal was characterized by Hofstede (1980) as collectivist, and recent data from the GLOBE project (House, Hanges, Javidan, Dorfman, \& Gupta. 2004; Jesuino, 2002) continue to classify the country as (in-group) collectivistic.

We conducted the current study with three goals in mind: (a) to test the unique contribution of well-known predictors of SWB (i.e., Big Five personality traits, attachment style, and satisfaction with relationships), (b) to test whether attachment style and satisfaction with social relationships mediate the association between personality and SWB, and (c) to test cultural similarities and differences in $a$ and $b$. Based on previous theory and research, we expected extroversion, neuroticism, satisfaction with relationships, and attachment style to predict SWB. We also expected that attachment style and satisfaction with relationships would mediate the association between personality traits and SWB. Finally, we expected that in Portugal and Mozambique, the impact of satisfaction with relationships on SWB would be greater than in the United States, because of the greater degree of collectivism in those nations.

To address each of our objectives, we developed a hypothesized model in which personality was defined as the main independent variable because of its trait and inborn characteristics. Attachment style, also a relatively stable and partly innate characteristic, but one that is mainly developed through early relationships experiences, was defined as a mediator between personality and current satisfaction with relationships. Personality and attachment style were defined as predictors of satisfaction with relationships because those trait characteristics are believed to determine the way individuals relate with others. Finally, satisfaction with relationships was defined apart from SWB because we wanted to specifically test its contribution to overall SWB in the three countries, although it can also be considered a dimension of life satisfaction. ${ }^{1}$

\section{Method}

\section{Participants}

Our sample comprised 1,576 university students from three different continents and countries: North America (North Carolina, USA), Africa (Maputo, Mozambique), and Europe (Lisbon, Portugal). Of the total number of participants, 497 were students at East Carolina University, aged between 18 and 54 years old $(M=19, S D=0.13 ; 64.3 \%$ female), 544 were students at Eduardo Mondlane University, aged between 17 and 45 years old $(M=25.18, S D=0.23 ; 42.8 \%$ female), and 533 were students at several universities in Lisbon, aged between 17 and 66 years old $(M=23, S D=0.35 ; 56.4 \%$ female $)$.

\section{Measures}

To measure the variables in the present study, we used six scales. In the American sample we used an English version of the scales and in the Portuguese and the Mozambican samples we 
used a Portuguese version of the scales. Below we present each scale, their characteristics, and the psychometric properties of the latent and observed variables used in our study, using SEM analysis. $^{2}$

Satisfaction With Life Scale (SWLS; Diener, Emmons, Larsen, \& Griffin, 1985; Portuguese Version: Neto, 1993). The SWLS measures global judgments of life satisfaction using five items. It was measured with a 7-point scale, from 1 (strongly disagree) to 7 (strongly agree). A one-factor model using confirmatory factor analysis (CFA) indicated high levels of reliability for the SWLS in all three samples: United States: $\chi^{2}=3.5, p=.18(\mathrm{CFI}=1$; GFI $=1$; SRMR $=.01)$; Mozambique: $\chi_{2}^{2}=31.3, p<.01(\mathrm{CFI}=.96 ; \mathrm{GFI}=.97$; SRMR $=.04)$; and Portugal: $\chi_{2}^{2}=10.5, p=.01$ $(\mathrm{CFI}=.99 ; \mathrm{GFI}=.99 ; \mathrm{SRMR}=.02)$.

Positive and Negative Affect Schedule (PANAS; Watson, Clark, \& Tellegen, 1988; Portuguese version: Galinha \& Ribeiro, 2005). The PANAS measures positive affect (PA) and negative affect (NA) using a list of 20 emotions. Participants are asked how much they experienced each emotion (during the last few days) on a scale from (1) very slightly or not at all to (5) extremely. A model with two correlated factors (PA and NA) fit the data well (better than the uncorrelated model), indicating high levels of reliability, respectively, in all three samples: United States: $\chi_{8}^{2}=$ $29.4, p<.01(\mathrm{CFI}=.97 ; \mathrm{GFI}=.98 ; \mathrm{SRMR}=.05)$; Mozambique: $\chi_{8}^{2}=20.6, p=.01(\mathrm{CFI}=.97$; $\mathrm{GFI}=.99 ; \mathrm{SRMR}=.03)$; and Portugal: $\chi_{8}^{2}=26.5, p<.01(\mathrm{CFI}=.98 ; \mathrm{GFI}=.98 ; \mathrm{SRMR}=.04)$.

Personal Wellbeing Index (PWI; International Wellbeing Group, 2006; Portuguese version [BEP]: Ribeiro \& Cummins, 2008). The PWI measures personal satisfaction with eight life domains: standard of living, health, achieving in life, relationships, safety, community connectedness, future security, and spirituality/religion. Participants are asked to respond to items using a 0 (completely dissatisfied) to 10 (completely satisfied) scale. Each dimension contributes independently to the variance of global satisfaction with life. Again, a one-factor model fit the data well, indicating high levels of reliability in all three samples: United States: $\chi_{2}^{2}=18.2, p<.01(\mathrm{CFI}=.98$; $\mathrm{GFI}=$ .98 ; SRMR $=.04)$; Mozambique: $\chi_{2}^{2}=11.8, p<.01(\mathrm{CFI}=.95$; GFI $=.99$; SRMR $=.03)$; and Portugal: $\chi_{2}^{2}=19.7, p<.01(\mathrm{CFI}=.95 ; \mathrm{GFI}=.98 ; \mathrm{SRMR}=.04)$.

Adult Attachment Scale-R (AAS-R; Collins \& Read, 1990; Portuguese version [EVA]: Canavarro, 1999). The AAS-R measures attachment in adult relationships on three dimensions: close (evaluates comfort in establishing close and intimate relationships), depend (evaluates the feeling of being able to depend on others in situations of need, level of trust in others), and anxiety (evaluates an individual's level of worry about the possibility of being abandoned, rejected, or not loved). The scale consists of 18 items, answered using a 1 (not at all characteristic) to 5 (very characteristic) response format. Three latent variables (anxiety, depend, and close) measuring one higher order factor (attachment) model fit the data well. Anxiety and depend are measured by three observed variables, and close is measured by one item. The model indicates high levels of reliability in all three samples: United States: $\chi_{12}^{2}=16.6, p=.17(\mathrm{CFI}=1$; GFI $=.99$; SRMR $=$ $.03)$; Mozambique: $\chi_{12}^{2}=20.9, p=.05(\mathrm{CFI}=.98 ; \mathrm{GFI}=.99$; SRMR $=.03)$; and Portugal: $\chi_{12}^{2}=$ $22.8, p=.03(\mathrm{CFI}=.99 ; \mathrm{GFI}=.99 ; \mathrm{SRMR}=.03)$.

Big Five Inventory (BFl; John \& Srivastava, 1999). The BFI measures the personality traits of extroversion, conscientiousness, agreeableness, neuroticism, and openness to experience. The inventory consists of 44 items ( 8 to 10 items per scale), answered using a 1 (strongly disagree) to 5 (strongly agree) response scale. Confirmatory factor analysis of a model with two correlated latent variables - extroversion, measured by three items, and neuroticism, measured by two items indicated high levels of reliability in all three samples: United States: $\chi_{5}^{2}=9.1, p=.10$ (CFI = .99; $\mathrm{GFI}=.99$; SRMR $=.04)$; Mozambique: $\chi_{5}^{2}=3.8, p=.59(\mathrm{CFI}=1$; GFI $=1$; SRMR $=.02)$; and Portugal: $\chi_{5}^{2}=12.8, p=.03(\mathrm{CFI}=.97 ; \mathrm{GFI}=.99 ; \mathrm{SRMR}=.04)$.

Satisfaction with relationships. Participants' satisfaction with relationships was measured through four items: "How satisfied are you with . . . your partner (boyfriend/girlfriend), the family you live 
with, your friends and neighbors, your colleagues (work/university)." The items were measured using a 5-point scale from "very little or not at all satisfied" to "extremely Satisfied." We developed a confirmatory factor analysis of a model with three correlated latent variables: satisfaction with partner (measured by one item); satisfaction with nuclear family (measured by one item); satisfaction with other relationships (measured by two items; e.g., satisfaction with friends and neighbors, satisfaction with colleagues). This model showed high levels of reliability for all three samples: United States: $\chi^{2}=0.1, p=.80(\mathrm{CFI}=1$; GFI $=1$; SRMR $=.00)$; Mozambique: $\chi_{1}^{2}=$ $00.0, p=.96(\mathrm{CFI}=1 ; \mathrm{GFI}=1 ; \mathrm{SRMR}=.00)$; and Portugal: $\chi_{1}^{2}=6.8, p=.01(\mathrm{CFI}=.96 ; \mathrm{GFI}=$ $.99 ; \mathrm{SRMR}=.02)$.

\section{Procedure}

After obtaining permission from the universities and teachers involved, students in the Mozambican and the Portuguese samples were invited, at the end of classes, to participate in a study about SWB and relationship experiences. The self-report questionnaire lasted on average 35 min. Prior to completing the survey, participants were informed about the confidentiality and the anonymity of the questionnaire in accordance with the ethical standards of the American Psychological Association (APA). The students who did not volunteer were free to leave the classrooms. Students were informed that they were free to answer only the questions that they wished. An e-mail address of the researcher was given for any questions related to the research project. Data collection for the U.S. sample was identical, except that participants completed the questionnaire online as one of several options available for obtaining course credit. Data in the three countries were collected during the winter of 2010.

\section{Results}

For the statistical analysis of the data, we used a variance-covariance matrix of the items with pairwise deletion for missing data. Parameters were estimated using the maximum likelihood algorithm, with AMOS (18th version) software (Arbuckle, 2009).

\section{Measurement Equivalence Across Cultures}

We first tested the measurement model to ensure metric equivalence across the three samples. This was achieved by defining a correlational model with all the latent variables in the study. To represent each latent variable, based on a preliminary analysis of each measure, we selected the three observed variables that, simultaneously, showed the best regression loadings in the three samples and varied the same in the three samples. The measurement model was specified by five correlated latent variables (see Figure 1): (1) attachment style, a second order latent variable inversely measured by anxiety with relationships and positively by comfort in establishing close relationships and being able to depend on others; (2) extroversion and (3) neuroticism, two first order latent personality trait variables; (4) satisfaction with relationships, a second order latent variable measured by satisfaction with nuclear family, with partner, with other relatives, and with friends and colleagues; and (5) subjective well-being (SWB), one second order dependent variable explained positively by global satisfaction with life, satisfaction with life in specific domains, positive affect (PA), and inversely by negative affect (NA).

This initial model was specified with three items measuring each latent variable. We first tested this model in the American sample, and it showed adequate fit: $\chi_{446}^{2}=877.2, p<.01(\mathrm{CFI}=$ $.91 ; \mathrm{GFI}=.90 ; \mathrm{RMSEA}=.04 ; \mathrm{SRMR}=.06)$. Almost all of the observed variables had standardized factor loadings above .40 , indicating good construct validity of the first order latent 
variables, except the item BFI24R (i.e., "I see myself as someone who is emotionally stable, not easily upset") in the neuroticism latent variable, which loaded .16.

We followed our analysis by testing the measurement model between the three samples (American, Mozambican, and Portuguese) using a multi-group analysis. The initial model yielded a $\chi_{1338}^{2}=2655.7, p<.01(\mathrm{CFI}=.89 ; \mathrm{GFI}=.90 ; \mathrm{RMSEA}=.03 ; \mathrm{SRMR}=.06)$. Analyzing the construct validity of the model in the Mozambican and the Portuguese samples, we found two observed variables with low factor loadings, both measuring the close dimension of attachment: AASR6 (i.e., "I do not worry about someone getting too close to me") and AASR17R (i.e., "Romantic partners often want me to be emotionally closer than I feel comfortable being"). We opted to delete these two items and Item BFI24R from the model because of the low factor loadings; as a result, the final model measured the latent variable neuroticism with two observed variables and the variable close with one observed variable (all other latent variables in the model were measured by three observed variables). This resulted in a final multigroup measurement model with adequate fit indices, $\chi_{999}^{2}=1,905.7, p<.01(\mathrm{CFI}=.91$; GFI $=.92$; RMSEA $=$ .02 ; SRMR $=.06$ ). The construct validity of the first order latent variables was supported-all the regression loadings were above .3. With regard to the second order latent variables, all the regression loadings were above .3 , except in the American sample, where NA loaded -.23 on SWB and satisfaction with partner loaded .27 on satisfaction with relationships.

In the next step, we tested this measurement model in each sample separately. We found a $\chi_{333}^{2}=629.9, p<.01(\mathrm{CFI}=.93 ; \mathrm{GFI}=.92 ; \mathrm{RMSEA}=.04 ; \mathrm{SRMR}=.06)$ for the U.S. sample (Figure 1); a $\chi_{333}^{2}=514.2, p<.01(\mathrm{CFI}=.92 ; \mathrm{GFI}=.94$; RMSEA $=.03$; SRMR $=.05)$ for the Mozambican sample (Figure 2); and a $\chi_{333}^{2}=761.6, p<.05(\mathrm{CFI}=.90$; GFI $=.91$; RMSEA $=$ .05 ; SRMR $=.06$ ) for the Portuguese sample (Figure 3 ). The results indicate good fit indices in all samples in the study. Additionally, all the observed variables in the model in all samples showed adequate regression loadings on the latent variables.

Next, we tested the metric measurement equivalence of the model between the three samples. We compared the baseline model, $\chi_{999}^{2}=1,905.7, p<.05$ (CFI = .91; GFI = .92; RMSEA = .02; $\mathrm{SRMR}=.06)$ to a constrained model (constraining to equality all the factor loadings of the observed variables between the three countries), yielding a $\chi_{1,031}^{2}=1,944.1, p<.01$ (CFI = .91; $\mathrm{GFI}=.92 ; \mathrm{RMSEA}=.02 ; \mathrm{SRMR}=.06$ ). The difference between the baseline and the constrained models was $\Delta \chi_{32}^{2}=38.4, p=.20$, indicating metric measurement equivalence between the samples. In other words, the solution we obtained is equivalent between the three samples, with adequate fit indices, showing that the observed variables are measuring the same latent variables in each country and that a comparison of the structural effects is legitimate.

Finally, before turning to the structural model, we tested for the hypothesis of multicollinearity between the latent variables. We compared the fit of our model with two other models: (a) where all the latent variables were measuring a third order latent variable, $\Delta \chi^{2}{ }_{15}=106.8, p<$ .05 , and (b) where satisfaction with relationships was represented as a dimension of SWB, $\Delta \chi_{12}^{2}=$ $32.3, p<.05$. Our model was significantly better than these two, suggesting that the correlation between the variables in our study does not imply the problem of multicollinearity.

\section{Structural Relations Among Key Variables Across Cultures}

As can be seen from the standardized estimates in Figures 1 to 3, almost all latent variables are correlated with one another weakly to moderately. Notable exceptions are the Mozambican and the Portuguese correlation between satisfaction with relationships and SWB (>.80). We also note that neuroticism and SWB yielded moderate to high correlations in the American (-.77) and Portuguese (-.79) samples. Having obtained the factor structure and metric measurement equivalence of the model in all three samples, with acceptable fit indices, we turned to addressing each of the primary objectives of the present study. We started by analyzing a structural 


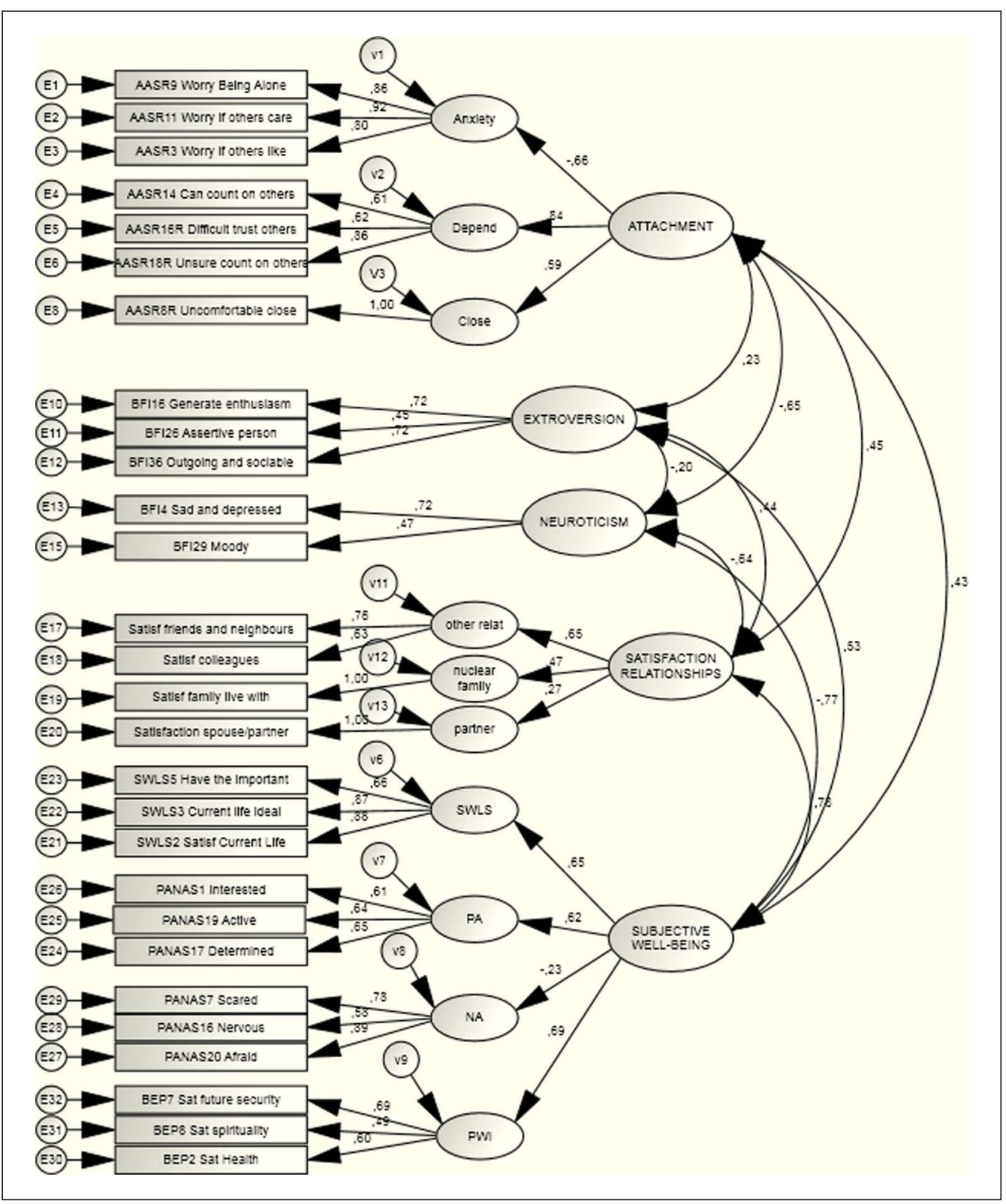

Figure I. Measurement Model,American Sample

Note. SWLS4 = Satisfaction With Life Scale Item 4 "I have the important things I want right now" (I- to 7-point scale); PANASI 7 - "Determined" (I- to 5-point scale); PWI7 "How satisfied are you with your future security?" (0- to I0-point scale);AASR9 - Adult Attachment Scale Item I4 "I know that people will be there when I need them" (I- to 5-point scale); BFI36 "Is outgoing and sociable" (I- to 5-point scale); Satisf. family live with "How satisfied are you with the family you live with (excluding your partner)?" (I- to 6-point scale).

model specifying personality, attachment, and satisfaction with relationships as independent variables and SWB as the dependent variable. Our first objective was to answer the question: What is the variable with the greatest contribution to SWB - extroversion, neuroticism, attachment style, or satisfaction with relationships - while controlling for each of the other variables? 


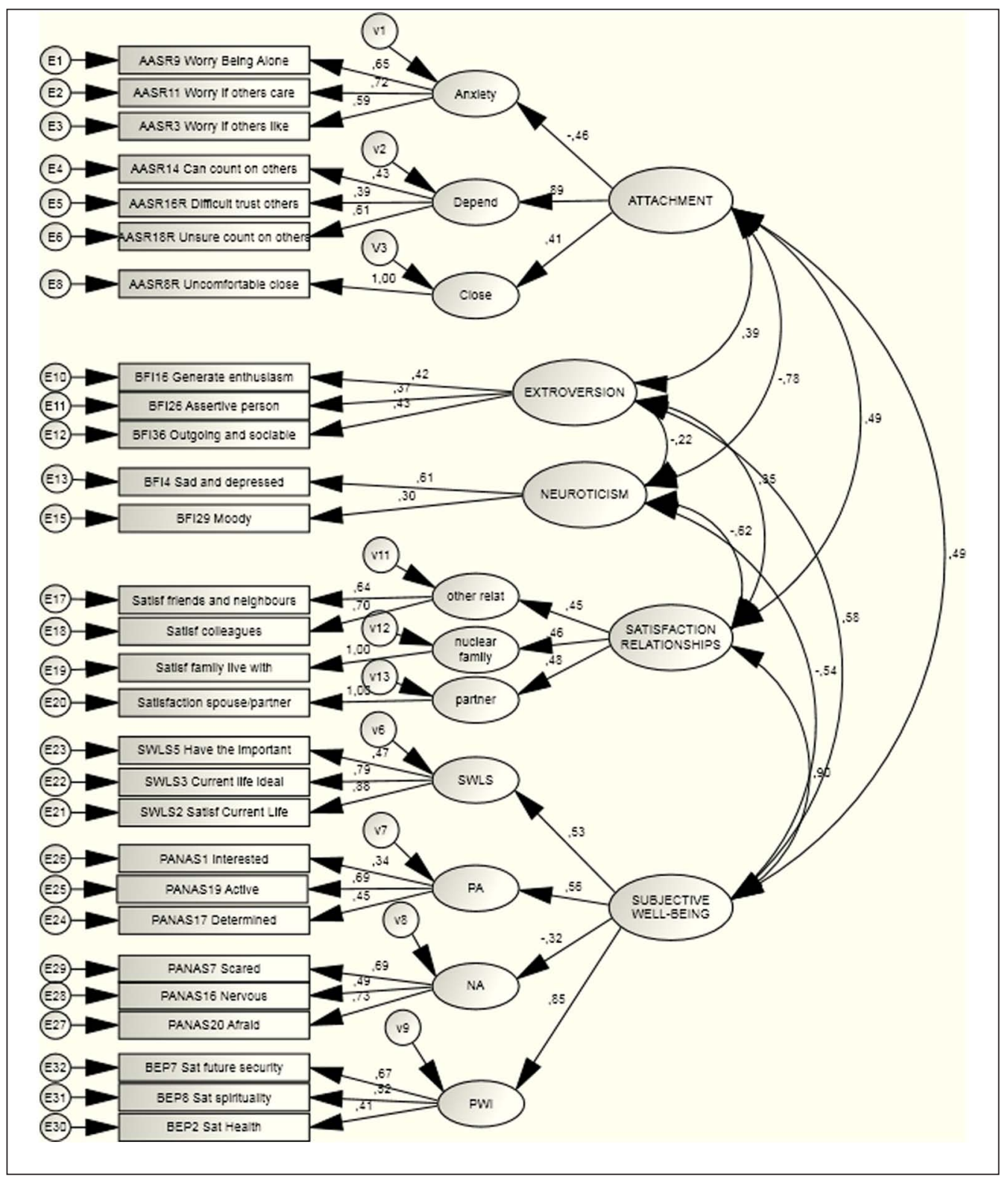

Figure 2. Measurement Model, Mozambican Sample

In the U.S. sample, according to the standardized regression coefficients, the main contributor to SWB was neuroticism (-.62), followed by satisfaction with relationships (.33) and extroversion (.31; see Figure 4). Attachment style, in contrast, showed a nonsignificant contribution to SWB. In other words, the moderate correlation that attachment showed with SWB in the measurement model became nonsignificant in the structural model, after the contribution of personality and satisfaction with relationships were included. The independent variables in the structural model explained $88 \%$ of the variance of SWB. 


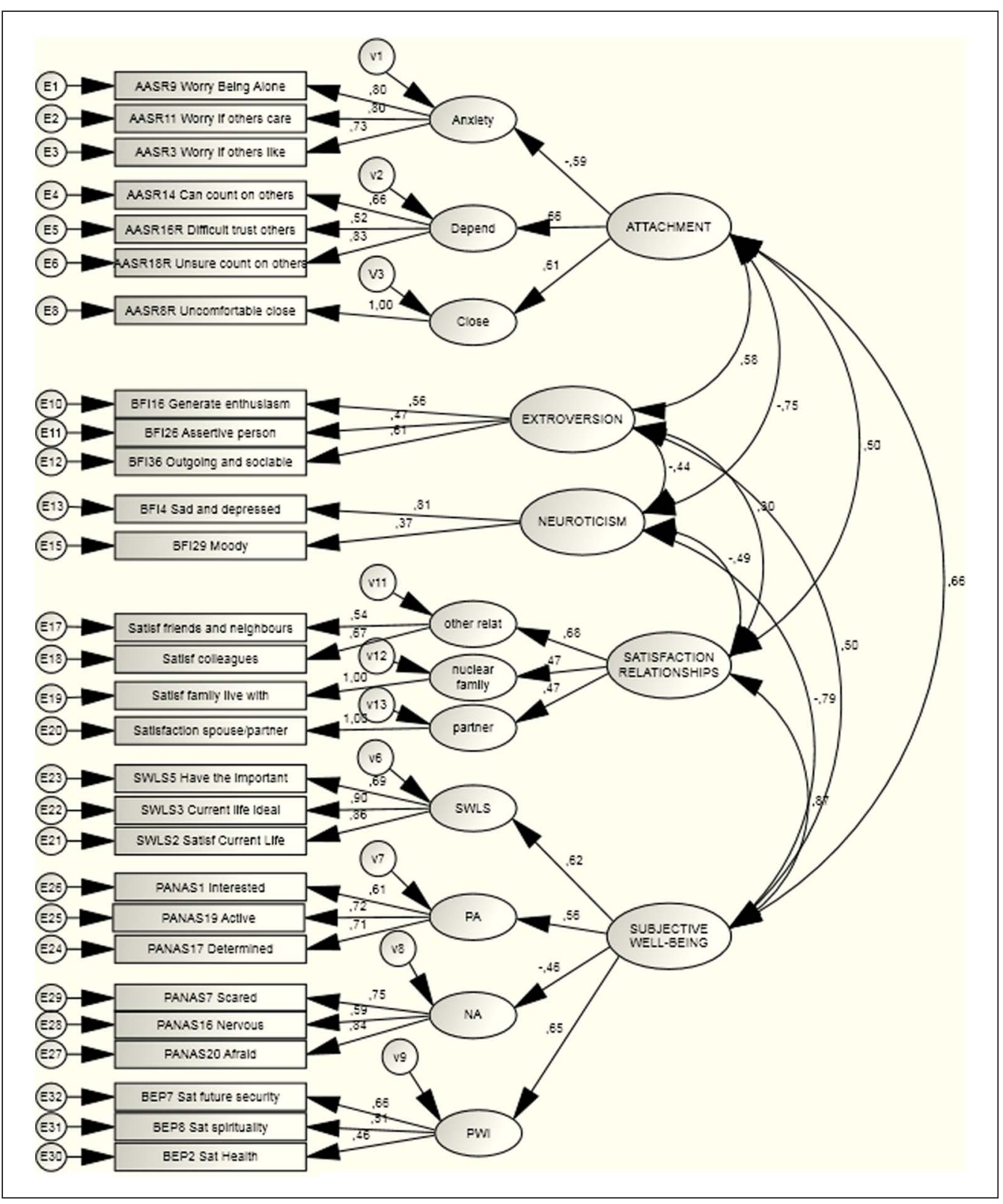

Figure 3. Measurement Model, Portuguese Sample

In the Mozambican sample, according to the standardized regression coefficients, the variable that showed the highest contribution to SWB was satisfaction with relationships (.81), followed by extroversion (.30; Figure 5). In contrast, neuroticism (.04) and attachment (.01) did not show significant contributions to SWB-despite their moderate relationships with SWB in the measurement model. The structural model demonstrates that these associations are not significant after accounting for the effect of satisfaction with relationships and extroversion. The independent variables explained $93 \%$ of the variability of SWB. 


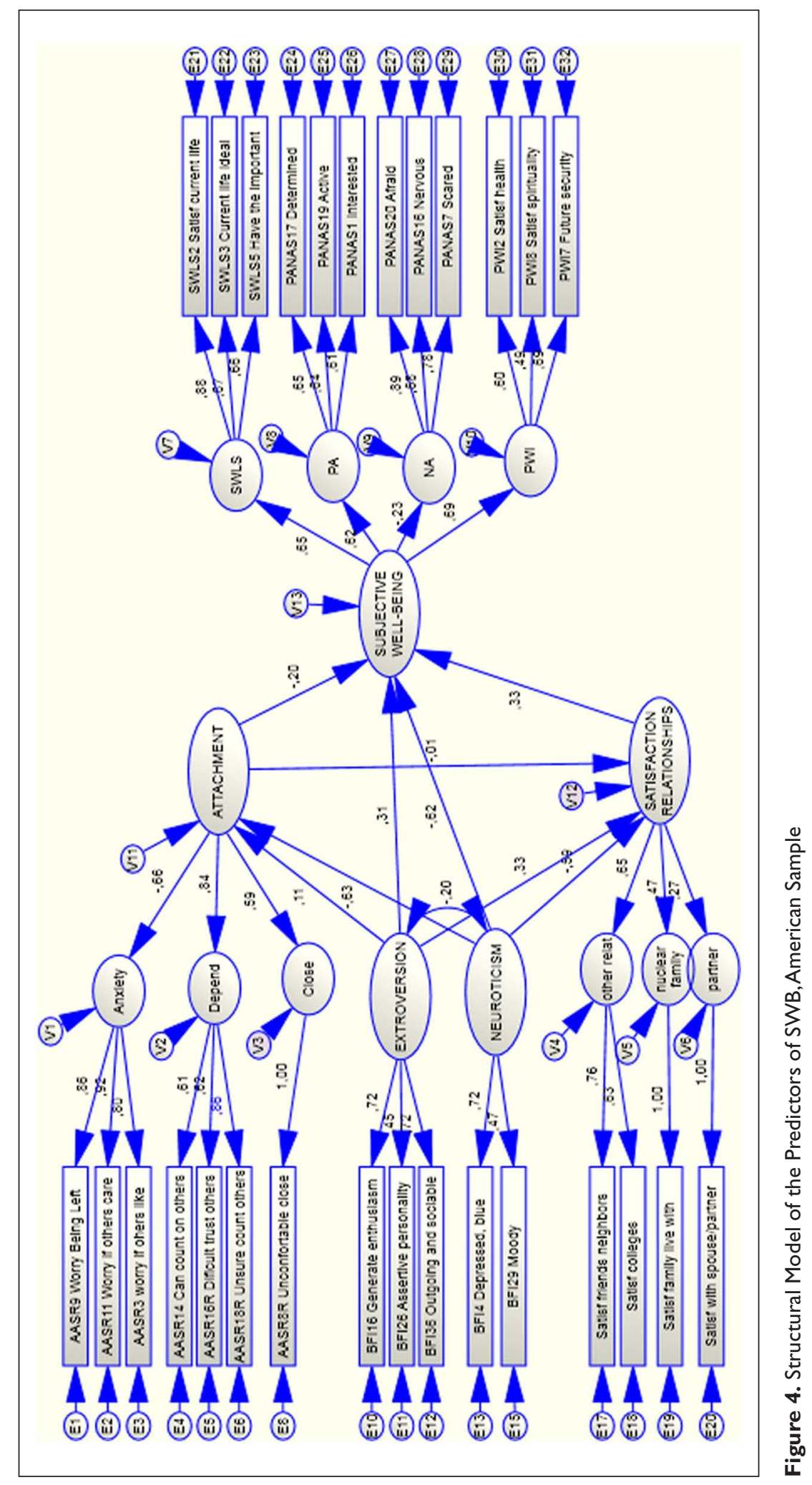




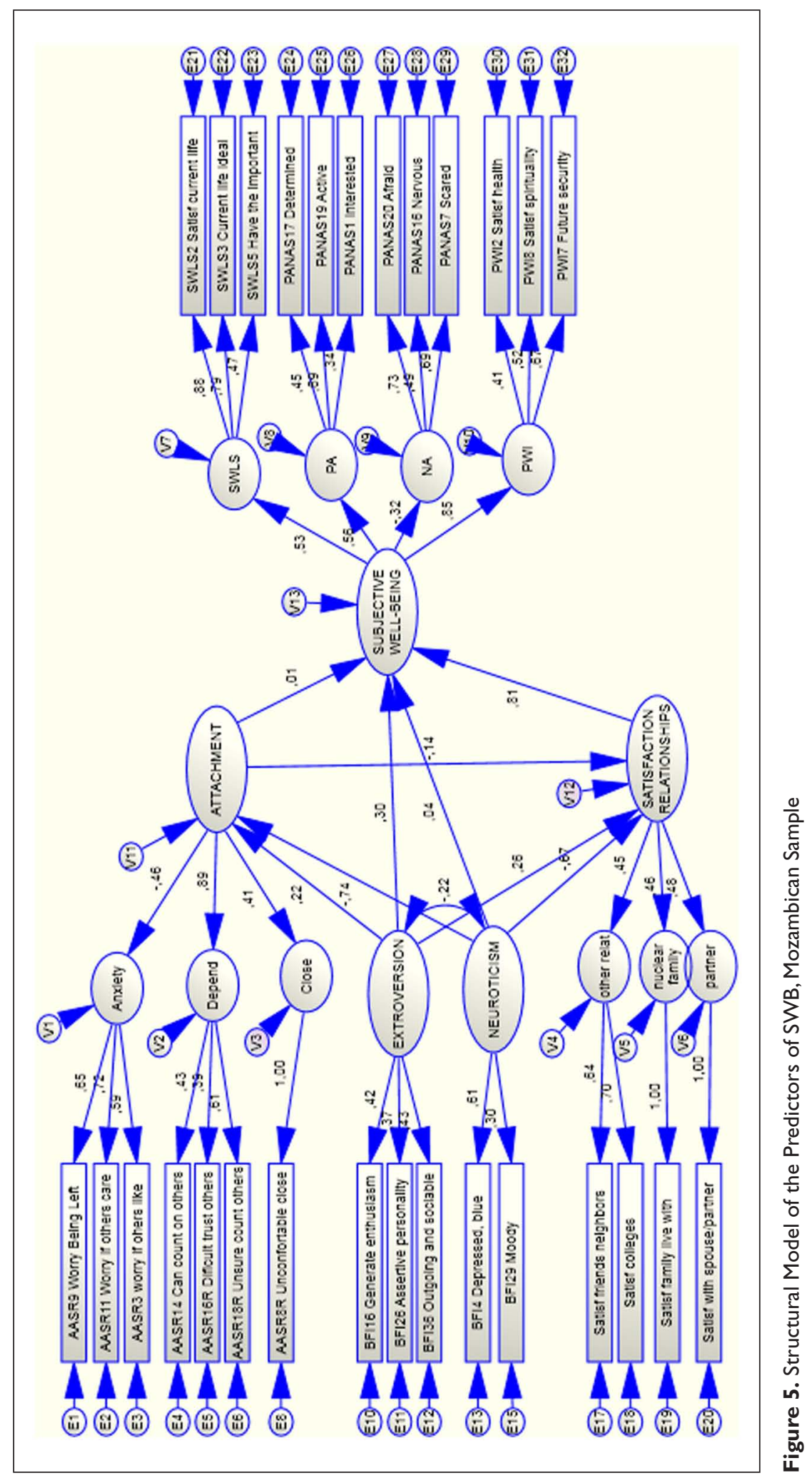


In the Portuguese sample, according to the standardized regression coefficients, the best predictor of SWB was satisfaction with relationships (.64), followed by neuroticism (-.51; Figure 6$)$. Extroversion (.16) and attachment security (-.14) showed only nonsignificant contributions to SWB. Once again, extroversion and attachment showed significant associations with SWB in the measurement model but lost their effect on SWB when controlling for the effects of satisfaction with relationships and neuroticism. The independent variables explained $97 \%$ of the variability of SWB. ${ }^{3}$

After identifying the culture-specific predictors of SWB, we next formally tested whether the structural relations among personality, attachment style, and SWB were different across the three cultures. To this end, we constrained the regression paths between the latent variables in the model across the three samples to be equal. The fit of the constrained model was significantly worse than the baseline model, in which the regression paths were allowed to vary across the three samples, $\Delta \chi_{20}^{2}=35.5, p=.02$, indicating that the effects between the latent variables in the three samples are different. Next, to clarify where the difference emerged, we tested the structural models two by two. We found significant differences between Portugal and Mozambique, $\Delta \chi_{10}^{2}=20.1, p=.03$, and between Portugal and the United States, $\Delta \chi_{10}^{2}=20.2, p=.03$. The United States and Mozambique were not significantly different, $\Delta \chi_{10}^{2}=12.7, p=.24{ }^{4}$

We next investigated potential cultural differences in satisfaction with relationships, personality, and attachment as predictors of SWB. For this purpose, we analyzed the unstandardized estimates. First, we examined differences between the three nations in the effect of satisfaction with relationships on SWB: high in Mozambique (2.14), moderate in Portugal (1.69), and low in the United States (.57). In this specific effect, Portugal and Mozambique were significantly different from the United States, $\Delta \chi_{1}^{2}=4.3, p=.04$. A second notable difference was the contribution of neuroticism to SWB: In the United States (-.62) and in Portugal (-.42), the association was negative and moderate, while in Mozambique it was nonsignificant (-.05); however, these differences were not significant, $\Delta \chi_{1}^{2}=1.1, p=.29$. Yet we can observe that for Americans, low neuroticism was a more important determinant of their global SWB than satisfaction with relationships. For the Mozambicans and the Portuguese, satisfaction with relationships was a more important determinant of their global SWB than neuroticism.

One similarity in the three samples was the nonsignificant effect of attachment on SWB. This result does not automatically mean that attachment is not an important predictor of SWB. Rather, it is explained by the moderate-high correlation that attachment shows with neuroticism in the American, Mozambican, and Portuguese measurement models (standardized estimates, respectively: $-.65 ;-.78 ;-.75)$.

\section{Mediational Analyses}

Our last objective was to test the mediating effect (a) of attachment between personality and SWB, (b) of attachment between personality and satisfaction with relationships, and (c) of satisfaction with relationships between personality and SWB, across the three samples of the study. The results indicate that there were no significant mediating effects of attachment or satisfaction with relationships between personality and SWB (see Table 1). Instead, the results suggest a mediating effect of personality. Therefore, we explored an alternative model testing the mediating effect of neuroticism and extroversion between attachment and SWB. In the American sample, there was, in fact, a mediating effect of extroversion and neuroticism between attachment and SWB and between attachment and satisfaction with relationships. In the Portuguese sample, there was also a significant mediating effect of neuroticism between attachment and SWB. However, similar results were not observed in the Mozambican sample, where there were no mediating effects of personality. 


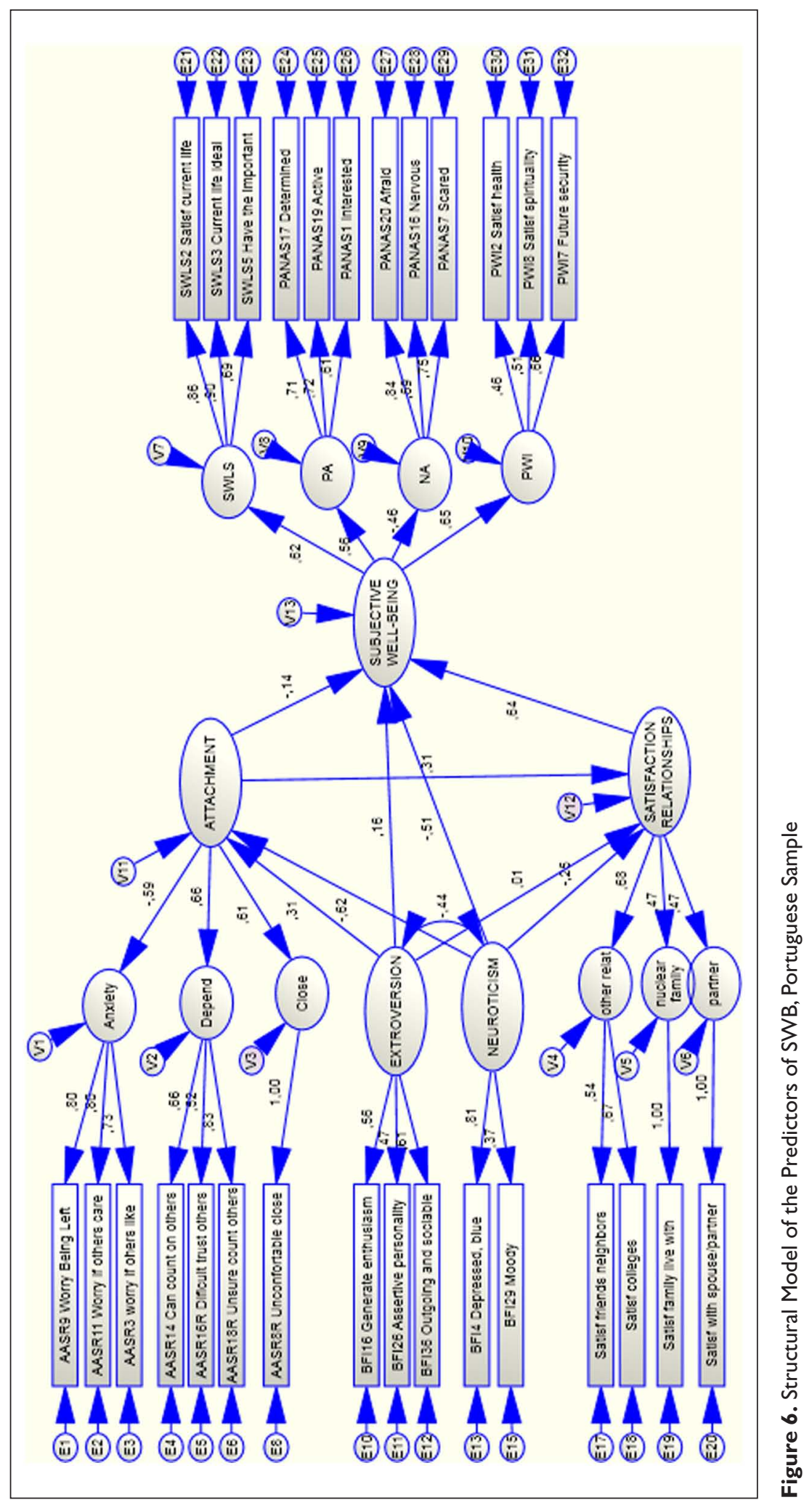


Table I. Significance of the Mediating Effects Between the Predictors of SWB

\begin{tabular}{|c|c|c|c|c|c|c|c|}
\hline \multirow[b]{2}{*}{ Mediator } & \multirow[b]{2}{*}{ Between } & \multicolumn{2}{|c|}{ US } & \multicolumn{2}{|c|}{ Moz } & \multicolumn{2}{|c|}{ Port } \\
\hline & & $z$ & $p$ & $z$ & $p$ & $z$ & $p$ \\
\hline ATT & EXTRO - SWB & -1.14 & .25 & .05 & .96 & -.67 & .50 \\
\hline ATT & NEURO - SWB & 1.53 & .13 & -.05 & .96 & .67 & .50 \\
\hline ATT & EXTRO - SR & -.09 & .93 & -.30 & .76 & 1.37 & 1.17 \\
\hline ATT & NEURO - SR & .09 & .93 & .30 & .76 & -1.45 & .15 \\
\hline SR & EXTRO - SWB & 1.62 & .10 & 1.39 & .16 & -.11 & .91 \\
\hline SR & NEURO - SWB & -1.58 & .11 & -1.12 & .26 & -1.37 & .17 \\
\hline SR & ATT - SWB & -.09 & .93 & -.30 & .76 & 1.43 & .15 \\
\hline NEURO & ATT-SWB & 2.65 & $.01 * *$ & -.26 & .79 & 2.42 & $.02 *$ \\
\hline EXTRO & ATT-SWB & 2.53 & $.01 * *$ & 1.82 & .07 & 1.62 & .11 \\
\hline EXTRO & ATT-SR & 2.71 & $.01 * *$ & $\mathrm{I} .47$ & .14 & .11 & .91 \\
\hline NEURO & ATT-SR & 3.06 & $.00 * *$ & 1.39 & .17 & 1.43 & .15 \\
\hline
\end{tabular}

Note. NEURO = Neuroticism; EXTRO = Extroversion;ATT = Attachment; $\mathrm{SR}=$ Satisfaction With Relationships; $\mathrm{SWB}=$ Subjective Well-Being.

$* p \leq .05$.**p $\leq .0 \mathrm{I}$.

\section{Discussion}

\section{Culture-Specific Predictors of SWB}

In this study, we tested the unique contribution of personality traits, attachment style, and satisfaction with relationships to subjective well-being (SWB). The best predictor of SWB in the American sample was personality - specifically, low neuroticism (i.e., emotional stability), contributing moderately to SWB. Extroversion and satisfaction with relationships also predicted SWB, with lower contributions. Attachment security showed no significant structural effect on SWB. In the Mozambican sample, the main predictor of SWB was satisfaction with relationships, followed by extroversion. Neuroticism and attachment security showed no significant effects on SWB. In the Portuguese sample, the main predictor of SWB was satisfaction with relationships, followed by low neuroticism. Extroversion and attachment had no significant effects on SWB.

The three samples were similar in the low or nonsignificant contribution of extroversion to SWB and the nonsignificant contribution of attachment to SWB. The significant but modest contributions of extroversion to SWB appear to contrast with previous studies showing consistently moderate to high associations between extroversion and SWB (Lucas, 2008). To interpret our findings, it is useful to compare the correlational (measurement) models (depicted in Figures 1 to 3 ) with the structural regression models (Figures 4 to 6), because only the latter present the unique contribution of each variable to SWB. Similar to past research, our correlational models with standardized estimates indicate moderate contributions of extroversion to SWB. It is only when extroversion and satisfaction with relationships are compared in the regression model that we observe small contributions (e.g., in the U.S. sample) to SWB, suggesting that these two variables are sharing variance. We can further suggest that part of the variance usually explained by extroversion is also being explained by satisfaction with relationships. Extroverts are more sociable and positive; therefore, they tend to have more social relationships and to be more satisfied with relationships (Diener \& Seligman, 2002). Therefore, in prior studies, probably extroverts are happier not only because of their personality traits but also because of the enhanced outcomes it provides in terms of relationship satisfaction. 
In none of the three samples did attachment contribute to SWB or to satisfaction with relationships. Securely attached people have a general positive attitude toward relationships, value and invest more in interpersonal relationships, and also consistently score higher in satisfaction with relationships and SWB (Mikulincer \& Shaver, 2007). The structural model, however, shows that attachment security does not significantly predict SWB or relationship satisfaction above and beyond personality. This result supports previous findings of a certain degree of overlap between personality traits and attachment styles (Bakker et al., 2004). Exploring these results, we found that in the American and Portuguese samples, the contribution of attachment style to SWB and to satisfaction with relationships was mediated by personality. Theoretically, personality is a trait characteristic of the individuals, mainly determined by temperamental (genetic) factors but also by the influence of contextual factors (Costa \& McCrae, 2000; Sanson et al., 2002). Attachment style is also a stable characteristic of the individuals, mainly determined by the relationship experiences during infancy (Mikulincer \& Shaver, 2007) but also determined by genetic factors (Crawford et al., 2007). Thus, based on personality and attachment theories, our model was specified to reflect the inborn and trait characteristics of personality as the main independent variable of the study and attachment (also a trait characteristic, but mainly developed through early relationship experiences) as a mediator. The data suggest, however, that personality is the mediator and can be predicted by attachment. These results imply that relationship experiences during infancy, and the internal models built, may be important determinants of our personality traits.

In sum, the similarities between the three samples are the low or nonsignificant contribution of extroversion and attachment to SWB that may be sharing variance, respectively, with satisfaction with relationships and neuroticism in the prediction of SWB.

\section{Cross-Cultural Comparison of the Predictors of SWB}

One of our primary goals was to analyze the moderating effect of culture in the relations between personality, attachment, satisfaction with relationships, and SWB. We compared our model based on the American sample with the models using Mozambican and Portuguese samples, addressing the need to test the universality of theories developed and empirically tested in America. The three samples showed significant differences in the structural model, meaning that the relations between the variables were not, in fact, universal. Following Norenzayan and Heine's (2005) triangular approach, we were able to identify that in the overall structural model, the Portuguese sample was significantly different from the Mozambican and from the American sample, while these two countries were not significantly different from each other. Considering this result, we can say that language and common historical background are not explaining the results, because in that case Portugal and Mozambique would be more alike.

On the other hand, a closer inspection of the results reveals that the main difference between the three countries was the contribution of satisfaction with relationships to SWB: low in the United States, moderate in Portugal, and high in Mozambique. Considering this specific relationship, Portugal and Mozambique appear to be more alike - and different from the United States. In this case, national differences in values on the individualism-collectivism continuum (Hofstede, 1980; Jesuino, 2002; Triandis, 1989) and in wealth (IMF, 2011; World Bank, 2011) may provide a better explanation for the results. Previous studies have found that people from developing countries rely on relationships as a means of survival. The group supports the individual in times of need, making it advantageous to be cooperative and seek connections with others. People from richer countries, in contrast, rely mainly on themselves and may not see relationships as essential for SWB (Veenhoven, 1999). According to Triandis (1989), in general, modernized Western countries are highly individualistic, whereas developing nations are more collectivistic. Therefore, individualism-collectivism values seem to be associated with economic level and also 
to construal of the self as interdependent (Markus \& Kitayama, 1991). According to the world ranking, we can classify Mozambique as a very poor country (121st in world ranking) and Portugal as a poor country (36th to 38th in world ranking), and both are considered to be collectivist. America, by comparison, is a very rich country and is considered to be individualistic. Thus, the role of satisfaction with relationships in predicting SWB across the three samples of our study supports the hypothesis of an association between the economic level of the country and its position in the individualist-collectivist values continuum.

\section{Measurement Issues and Limitations}

Measures of psychological constructs developed in Anglo-Saxon countries pose frequent difficulties, in terms of obtaining equivalent measurement, when employed in countries with different languages and cultures. Our results suggest that not only might language differences account for difficulties in obtaining measurement equivalence, but probably also differences in the definition and operationalization of the concepts. Therefore, the development of international measures of psychological constructs is important to future transcultural studies.

Limitations of the present study include the fact that the U.S. sample collection procedure was different from the Mozambican and the Portuguese samples. The U.S. participants completed the questionnaire online, and the Mozambican and the Portuguese participants completed the questionnaire in the classroom. The different procedure, though, did not invalidate the metric invariance of the measures. However, in the second order latent variables of the American sample, two factor loadings still remained below .3. It should be also noted that our samples are not nationally representative - thus, generalization needs some caution. Finally, it would be interesting to analyze gender differences in the relations between the variables in the study. Although these analyses are beyond the scope of the present article, they suggest important directions for future research.

\section{Conclusion}

The current research provides new knowledge regarding cultural similarities and differences in predictors of SWB among Americans, Portuguese, and Mozambicans. In the American sample, emotional stability was a more important predictor of global SWB than satisfaction with relationships. On the contrary, in the Mozambican sample, relationships were far more important predictors of SWB than emotional stability. In the Portuguese sample, emotional stability and satisfaction with relationships were equally important predictors of SWB. The samples in the three countries were similar in demonstrating the nonsignificant impact of attachment on SWB and the low or nonsignificant contribution of extroversion to SWB (above and beyond the contribution of the other predictors). When analyzed alone, attachment and extroversion show higher contributions to SWB, but when analyzed conjointly with neuroticism and satisfaction with relationships, these variables show lower unique contributions, suggesting that they are sharing variance in the prediction of SWB. This phenomenon is observed across the three samples and stresses the importance of analyzing, conjointly, multiple predictors of SWB.

\section{Acknowledgments}

We thank the Universidade Eduardo Mondlane, East Carolina University, Instituto Superior Técnico, Universidade Autónoma de Lisboa, and Instituto Superior de Ciências do Trabalho e da Empresa for their support and all the teachers and students who collaborated in the collection of the samples of the study. 


\section{Declaration of Conflicting Interests}

The author(s) declared no potential conflicts of interest with respect to the research, authorship, and/or publication of this article.

\section{Funding}

The author(s) disclosed receipt of the following financial support for the research, authorship, and/or publication of this article: Project financed by the Portuguese Sciences and Technologies Foundation BPD / $26479 / 2006$.

\section{Notes}

1. No prior studies identified the direction of causality between satisfaction with relationships and SWB. However, since it was not possible to draw an association path between both latent variables in our model - because SWB is a second order variable and has a variance of error attached - we opted to specify satisfaction with relationships as a predictor of SWB.

2. We also analyzed the measures in our study using Cronbach's alpha, yet some coefficients were below the recommended criteria. This can be due to the reduced number of items for each measure in the study. For that reason, we developed a factorial analysis to test the psychometric quality of our measures using SEM, because it controls for the measurement error of the items (Bollen, 1989). In the Results section, we further demonstrate the quality of our measurement model using a multigroup analysis, yielding good fit indices and metric equivalence between the three samples. Further data on all measures are available from the authors upon request.

3. To address the stability of the estimated parameters, we tested our structural model using the full information maximum likelihood approach to the missing data, yielding a $\chi_{999}^{2}=1,801.6, p<.05(\mathrm{CFI}=.92$; RMSEA $=.02$ ). Results showed the stability of the significant effects between the variables in each country and the differences between countries $\Delta \chi_{20}^{2}=31.4, p=.05$.

4. In a supplementary analysis, we controlled for age and sex in the structural model to be sure that the differences observed between the samples were not due to different distributions of age or sex in the samples. The structural effects remained identical.

\section{References}

Arbuckle, J. L. (2009). AMOS 18 reference guide (Version 18) [computer software]. Chicago: SPSS Inc.

Arthaud-Day, M., Rode, J., Mooney, C., \& Near, J. (2005). The subjective well-being construct: a test of its convergent, discriminant, and factorial validity. Social Indicators Research, 74, 445 -476.

Bakker, W., van Oudenhoven, J., \& van der Zee, K. I. (2004). Attachment styles, personality, and Dutch emigrants' intercultural adjustment. European Journal of Personality, 18(5), 387-404.

Birnbaum, G., Orr, I., Mikulincer, M., \& Florian, V. (1997). When marriage breaks up: Does attachment style contribute to coping and mental health? Journal of Social and Personal Relationships, 14(5), 643-654.

Bollen, K. A. (1989). Structural equations with latent variables. New York: John Wiley \& Sons.

Canavarro, M. (1999). Relações afectivas e saúde mental [Affective relationships and mental health]. Coimbra, Portugal: Quarteto Editora.

Cohen, S. (2004). Social relationships and health. American Psychologist, 59(8), 676-684.

Collins, N. L., \& Read, S. J. (1990). Adult attachment, working models, and relationship quality in dating couples. Journal of Personality and Social Psychology, 54, 644-663.

Costa, P. T., Jr., \& McCrae, R. R. (2000). A theoretical context for adult development. In T. D. Wachs \& G. A. Kohnstamm (Eds.), Temperament in context (pp. 1-21). Hillsdale, NJ: Erlbaum.

Crawford, T. N., Livesley, W. J., Jang, K. L., Shaver, P. R., Cohen, P., \& Ganiban, J. (2007). Insecure attachment and personality disorder: A twin study of adults. European Journal of Personality, 21, 191-208. 
Crossley, A., \& Langdridge, D. (2005). Perceived sources of happiness: A network analysis. Journal of Happiness Studies, 6(2), 107-135.

Demir, M. (2008). Sweetheart, you really make me happy: Romantic relationship quality and personality as predictors of happiness among emerging adults. Journal of Happiness Studies, 9(2), 257-277.

Diamond, L. M., Hicks, A. M., \& Otter-Henderson, K. D. (2008). Every time you go away: Changes in affect, behavior, and physiology associated with travel-related separations from romantic partners. Journal of Personality and Social Psychology, 95, 385-403.

Diener, E., \& Biswas-Diener, R. (2008). Happiness: Unlocking the mysteries of psychological wealth. Malden, MA: Blackwell Publishing.

Diener, E., Emmons, R. A., Larsen, R. J., \& Griffin, S. (1985). The satisfaction with life scale. Journal of Personality Assessment, 49, 71-75.

Diener, E., Gohm, C., Suh, E., \& Oishi, S. (2000). Similarity of the relations between marital status and subjective well-being across cultures. Journal of Cross-Cultural Psychology, 31, 419-436.

Diener, E., Oishi, S., \& Lucas, R. E. (2003). Personality, culture, and subjective well-being. Annual Review of Psychology, 54, 403-425.

Diener, E., \& Ryan, K. (2009). Subjective well-being: A general overview. South African Journal of Psychology, 39, 391-406.

Diener, E., \& Seligman, M. E. P. (2002). Very happy people. Psychological Science, 13, 81-84.

Diener, E., Suh, E., Lucas, R., \& Smith, H. (1999). Subjective well-being: Three decades of progress. Psychological Bulletin, 125, 276-302.

Digman, J. M. (1990). Personality structure: Emergence of the five-factor model. Annual Review of Psychology, 41, 417-440.

Dush, C., \& Amato, P. R. (2005). Consequences of relationship status and quality for subjective well-being. Journal of Social \& Personal Relationships, 22(5), 607-627.

Eaton, L., \& Louw, J. (2000). Culture and self in South Africa: Individualism-collectivism predictions. Journal of Social Psychology, 140(2), 210-217.

Galinha, I., \& Ribeiro, J. (2005). Contribuição para o estudo da versão portuguesa da Positive and Negative Affect Schedule (PANAS): II - Estudo Psicométrico [Contributions for the study of the Portuguese version of Positive and Negative Affect Schedule (PANAS): II - Psychometric study]. Análise Psicológica, 23, 219-227.

Galinha, I., \& Ribeiro, J. (2008). Structure and stability of subjective well-being: A structure equation modelling analysis. Applied Research in Quality of Life, 3, 293-314.

Headey, B., Veenhoven, R., \& Wearing, A. (1991). Top-down versus bottom-up theories of subjective wellbeing. Social Indicators Research, 24, 81-100.

Helliwell, J. F., Barrington-Leigh, C., Harris, A., \& Huang, H. (2009). International evidence on the social context of well-being. In E. Diener, D. Kahneman, \& J. F. Helliwell (Eds.), International differences in well-being (pp. 3-15). Oxford, UK: Oxford University Press.

Henrich, J., Heine, S. J., \& Norenzayan, A. (2010). The weirdest people in the world? (Target article, commentaries, and response). Behavioral and Brain Sciences, 33, 61-83, 111-135.

Hofstede, G. (1980). Culture's consequences. Beverly Hills, CA: Sage.

House, R. J., Hanges, P. J., Javidan, M., Dorfman, P. W., \& Gupta, V. (2004). Culture, leadership and organizations: The GLOBE study of 62 societies. Thousands, CA: Sage.

International Monetary Fund. (2011). World Economic Outlook Database, April 2011: Nominal GDP list of countries. Data for the year 2010. Retrieved July 1, 2011, from http://www.imf.org/external/pubs/ft/ weo/2011/01/weodata/index.aspx

International Wellbeing Group. (2006). Personal Wellbeing Index. Melbourne: Australian Centre on Quality of Life, Deakin University. Retrieved at August 1, 2011, from http://www.deakin.edu.au/research/ acqol/instruments/wellbeing-index/pwi-a-english.pdf

Jesuino, J. C. (2002). Latin Europe cluster: From South to North. Journal of World Business, 37, 81-89. 
John, O., \& Srivastava, S. (1999). The Big-Five Trait taxonomy: History, measurement, and theoretical perspectives. In L. A. Pervin \& O. P. John (Eds.), Handbook of personality: Theory and research (pp. 102-139). New York: Guilford Press.

Kahneman, D., \& Krueger, A. B. (2006). Developments in the measurement of subjective well-being. Journal of Economic Perspectives, 20, 3-24.

Kang, S., Shaver, P. R., Sue, S., Min, K., \& Jing, H. (2003). Culture-specific patterns in the prediction of life satisfaction: Roles of emotion, relationship quality, and self-esteem. Personality and Social Psychology Bulletin, 29, 1596-1608.

Karney, B. R., \& Bradbury, T. N. (1995). The longitudinal course of marital quality and stability: A review of theory, method, and research. Psychological Bulletin, 118, 3-34.

Kwan, V., Bond, M., \& Singelis, T. (1997). Pancultural explanation for life satisfaction: Adding relationship harmony to self-esteem. Journal of Personality and Social Psychology, 73, 1038-1051.

Lucas, R. E. (2008). Personality and subjective well-being. In R. J. Larsen \& M. Eid (Eds.), The science of subjective well-being (pp. 171-194). New York: Guilford Press.

Lyubomirsky, S., King, L., \& Diener, E. (2005). The benefits of frequent positive affect: Does happiness lead to success? Psychological Bulletin, 131(6), 803-855.

Markus, H. R., \& Kitayama, S. (1991). Culture and the self: Implications for cognition, emotion, and motivation. Psychological Review, 98, 224-253.

Mikulincer, M., \& Shaver, P. R. (2005). Attachment theory and emotions in close relationships: Exploring the attachment-related dynamics of emotional reactions to relational events. Personal Relationships, 12(2), 149-168.

Mikulincer, M., \& Shaver, P. R. (2007). Attachment in adulthood: Structure, dynamics, and change. New York: Guilford Press.

Mozambican Government Official Site. (2011, May 20). Resenha histórica do país desde o período colonial até ao período pós - independência [Summary of the history of the country from the colonial period to the post independency period]. Retrieved from http://www.portaldogoverno.gov.mz

Myers, D. G. (1999). Close relationships and the quality of life. In D. Kahneman, E. Diener, \& N. Schwarz (Eds.), Well-being: The foundations of hedonic psychology (pp. 374-380). New York: Russell Sage Foundation.

Neto, F. (1993). Satisfaction With Life Scale: Psychometric properties in an adolescent sample. Journal of Youth and Adolescence, 22(2), 125.

Noftle, E. E., \& Shaver, P. R. (2006). Attachment dimensions and the big five personality traits: Associations and comparative ability to predict relationship quality. Journal of Research in Personality, 40(2), 179-208.

Norenzayan, A., \& Heine, S. J. (2005). Psychological universals: What are they and how can we know? Psychological Bulletin, 135, 763-784.

Oyserman, D., Coon, H. M., \& Kemmelmeier, M. (2002). Rethinking individualism and collectivism: Evaluation of theoretical assumptions and meta-analyses. Psychological Bulletin, 128(1), 3-72.

Pietromonaco, P. R., \& Barrett, L. F. (1997). Working models of attachment and daily social interactions. Journal of Personality and Social Psychology, 73, 1409-1423.

Pinquart, M., \& Sörensen, S. (2000). Influences of socioeconomic status, social network, and competence on subjective well-being in later life: A meta-analysis. Psychology and Aging, 15(2), 187-224.

Reis, H. T., Collins, W., \& Berscheid, E. (2000). The relationship context of human behavior and development. Psychological Bulletin, 126, 844-872.

Ribeiro, J., \& Cummins, R. (2008). O bem-estar pessoal: Estudo de validação da versão portuguesa da escala [Personal Wellbeing Index: Study of the Portuguese validation of the scale]. In L. Leal, J. PaisRibeiro, I. Silva, \& S. Marques (Eds.), Actas do $7^{\circ}$ congresso nacional de psicologia da saúde (pp. 505-508). Lisboa, Portugal: Instituto Superior de Psicologia Aplicada. 
Sanson, A., Hamphill, S., \& Smart, D. (2002). Temperament and social development. In P. Smith \& C. Hart (Eds.), Handbook of developmental cognitive science (pp.97-116). Malden, MA. Blackwell.

Schimmack, U., Oishi, S., \& Diener, E. (2005). Individualism: A valid and important dimension of cultural differences between nations. Personality \& Social Psychology Review, 9(1), 17-31.

Seligman, M. E. P. (1991). Learned optimism: How to change your mind and your life. New York: Knopf.

Suh, E., \& Oishi, S. (2004). Culture and subjective well-being: Introduction to the special issue. Journal of Happiness Studies, 5, 219-222.

Tidwell, M. O., Reis, H. T., \& Shaver, P. R. (1996). Attachment, attractiveness, and social interaction: A diary study. Journal of Personality and Social Psychology, 71(4), 729-745.

Tomlinson, J., Carmichael, C., Reis, H., \& Aron, A. (2010). Affective forecasting and individual differences: Accuracy for relational events and anxious attachment. Emotion, 10(3), 447-453.

Torquati, J. C., \& Raffaelli, M. (2004). Daily experiences of emotions and social contexts of securely and insecurely attached adults. Journal of Adolescent Research, 19, 740-758.

Triandis, H. C. (1989). The self and social behavior in differing cultural contexts. Psychological Review, 96(3), 506-520.

Uchida, Y., Kitayama, S., Mesquita, B., Reyes, J. A. S., \& Morling, B (2008). Is perceived emotional support beneficial? Well-being and health in independent and interdependent cultures. Personality and Social Psychology Bulletin, 34, 741-754.

Veenhoven, R. (1999). Quality-of-life in individualistic society: A comparison of 43 nations in the early 1990's. Social Indicators Research, 48(2), 157-186.

Watson, D., Clark, L. A., \& Tellegen, A. (1988). Development and validation of brief measures of positive and negative affect: The PANAS scales. Journal of Personality and Social Psychology, 54(6), 1063-1070.

White, J. K., Hendrick, S. S., \& Hendrick, C. (2004). Big five personality variables and relationship constructs. Personality \& Individual Differences, 37(7), 1519-1530.

World Bank. (2011). Gross domestic product (2010) (The World Bank: World Development Indicators database). Retrieved July 1, 2011, from http://siteresources.worldbank.org/DATASTATISTICS/Resources/ GDP.pdf 